\title{
Elbow Fracture
}

National Cancer Institute

\section{Source}

National Cancer Institute. Elbow Fracture. NCI Thesaurus. Code C27190.

A traumatic break in one or more of the bones composing the elbow joint. 